\title{
Knowledge, attitudes, and preventive practices about colorectal cancer among adults in an area of Southern Italy
}

\author{
Alessandra Sessa, Rossella Abbate, Gabriella Di Giuseppe, Paolo Marinelli \\ and Italo F Angelillo*
}

Address: Department of Public, Clinical and Preventive Medicine, Second University of Naples, Naples, Italy

Email: Alessandra Sessa - ale.sessa@hotmail.it; Rossella Abbate - rossella.abbate@libero.it; Gabriella Di Giuseppe - gabrydg@libero.it; Paolo Marinelli - paolo.marinelli@unina2.it; Italo F Angelillo* - italof.angelillo@unina2.it

* Corresponding author

Published: II June 2008

BMC Cancer 2008, 8:1|7| doi:10.|186/|47|-2407-8-17|
Received: 9 January 2008

Accepted: II June 2008

This article is available from: http://www.biomedcentral.com/I47I-2407/8/I7I

(c) 2008 Sessa et al; licensee BioMed Central Ltd.

This is an Open Access article distributed under the terms of the Creative Commons Attribution License (http://creativecommons.org/licenses/by/2.0), which permits unrestricted use, distribution, and reproduction in any medium, provided the original work is properly cited.

\begin{abstract}
Background: Colorectal cancer (CRC) is the second most commonly diagnosed cancer for both sexes in developed countries. This study assessed the knowledge, attitudes, and preventive practices regarding CRC of adults in Italy.

Methods: A random sample of II65 adults received a self-administered questionnaire on sociodemographic characteristics; knowledge regarding definition, risk factors, and screening; attitudes regarding perceived risk of contracting CRC and utility of screening tests; health-related behaviors and health care use; source of information.

Results: Only 18.5\% knew the two main modifiable risk factors (low physical activity, high caloric intake from fat) and this knowledge was significantly associated with higher educational level, performing physical activity, modification of dietary habits and physical activity for fear of contracting CRC, and lower risk perception of contracting CRC. Half of respondents identified fecal occult blood testing (FOBT) as main test for CRC prevention and were more knowledgeable those unmarried, more educated, who knew the main risk factors of $C R C$, and have received advice by physician of performing FOBT. Personal opinion that screening is useful for CRC prevention was high with a mean score of 8.3 and it was predicted by respondents' lower education, beliefs that CRC can be prevented, higher personal perceived risk of contracting CRC, and information received by physician about CRC. An appropriate behavior of performing FOBT if eligible or not performing if not eligible was significantly higher in female, younger, more educated, in those who have been recommended by physician for undergo or not undergo FOBT, and who have not personal history of precancerous lesions and familial history of precancerous lesions or CRC.
\end{abstract}

Conclusion: Linkages between health care and educational systems are needed to improve the levels of knowledge and to raise CRC screening adherence.

\section{Background}

Malignant neoplasms from all cancers are the second leading cause of death after heart disease and colorectal cancer (CRC) is the third most commonly diagnosed form of cancer in each sex and the second for both sexes combined in essentially all economically developed countries 
[1]. At current rates, approximately $6 \%$ of individuals will develop CRC within their lifetime, and about half of them will die from this disease [2]. In the United States, it is estimated that 148,810 new cases of CRC will be diagnosed in the 2008 with 49,960 deaths [3], whereas in Italy in the period 2000-2003, there were 38,643 new cases [4] and, as regards mortality, in 2002 there were 29,734 deaths [5]. Due to the aging population and population growth, the expected numbers will increase in forthcoming years. Thus, prevention and early detection has immense public health importance. Indeed, the overwhelming evidence indicates that a vast majority of these cases and associated deaths could be reduced if diagnosed early enough and prevented by existing primary and secondary intervention. At least $70 \%$ of colon cancers may be preventable by focusing on modifiable risk factors and making moderate changes in diet and lifestyle [2] and secondary prevention is also critically important to prevent mortality. In the United States is recommended a fecal occult blood testing (FOBT) or lower endoscopy examination [3] and in Europe a FOBT [6]. In Italy, where a population based organized screening, in which all individuals in the target group are invited to take part, is under implementation, the majority of programs employ the FOBT $[7,8]$.

A high participation level of the general population is essential for prevention programs to succeed. The key to achieving adequate compliance is informing the community through an educational campaign about the nature and extent of the disease, as well as preventive measures to be used. Relatively little is known regarding current knowledge [9], attitudes [9,10], and behaviors about CRC in the general population [10-19], and such understanding is imperative. Therefore, the goal of this study was to characterize the levels of knowledge, attitudes, and preventive practices about CRC among a sample of adults in an area of Southern Italy.

\section{Methods}

A cross-sectional survey was conducted from November 2006 to March 2007. A random sample of 1165 parents of children attending three randomly selected public schools were recruited in the geographic area of the Campania region, in the South of Italy.

Before the study, permission and collaboration of the head of each school were obtained. A pilot study and pretest were carried out with a sample of 25 adults, similar to those included in the final study, in order to evaluate the comprehensibility of the wording of each question. Feedback was incorporated into the survey prior to the initial delivering. Data for the study were collected by selfadministered anonymous structured questionnaire. The questionnaires were delivered, in sealed envelope, to the children in each classroom by trained research assistants and requested were made that the survey be completed by one parent only. Each family also received a letter containing information about the purpose and objectives of the study, that participation was strictly voluntary, that the data collected would not be used for anything except the research aim. Confidentiality of responses was assured, and an envelope to facilitate the return of the completed questionnaire was made available. A respondent's consent was taken into account while filling the questionnaire. The questionnaire was divided into five major parts for ease of administration [see Additional file 1]. The sociodemographic section focused on personal characteristics of respondents, such as age, sex, marital status, educational level, occupational position, whether they were living alone or not, weight, and height; self-rated health and their personal or familial history of CRC. Body Mass Index (BMI) was calculated from self-reported weight and height by dividing weight in kilograms by height in meters squared. The self-reported height and weight have been demonstrated to be reliable with test-retest analyses $[20,21]$. Self-rated health was assessed on a ten-point Likert-type scale, with responses ranging from 1 (poor) to 10 (excellent). Knowledge was explored by requesting parents to answer a number of questions including definition, risk factors, and screening tests of CRC. This section elicited responses in a variety of formats: open for the definition; "yes", "no", and "do not know" for the screening tests; and closed-end with categorical (yes or no) for the risk factors. In the attitude section, the participants were also asked whether or not him/her perceived themselves to be at risk for contracting CRC and their opinion about the utility of screening tests for its prevention. Beliefs were measured on a three-point Likert-type scale anchored by disagree and agree and statement about risk perception and utility of screening tests on a ten-point Likert-type scale, with responses ranging from 1 (not at all) to 10 (very much). Questions about health-related behaviors and health care use included whether or not respondents perform physical activities, have modified their dietary habits and/or physical activity for fear of contracting CRC, have received advice of performing FOBT, have participated in preventive activities about CRC, and have undergone a test. Finally, respondents were also asked about the source of information in close-ended questions with multiple answers possible.

The study was approved by the Ethics Committee.

\section{Statistical analysis}

All statistical analyses were conducted in two steps. First, bivariate analyses tested the associations between potential explanatory variables and each outcome of interest by using appropriate test statistic. Second, variables associated with each outcome of interest with a $p$-value $\leq 0.25$ in bivariate analyses were entered into four separate mul- 
tivariable logistic and linear regression models, using a stepwise technique, for each of the main following outcomes of interest: knowledge of the two main modifiable risk factors of CRC (low physical activity, high caloric intake from fat) (Model 1); knowledge of FOBT as main test for CRC prevention (Model 2); positive attitude towards the utility of screening tests for CRC prevention (Model 3); appropriate behavior in undergoing FOBT if eligible or not undergoing FOBT if not eligible (Model 4). In all models, the independent variables included were the following: gender (male $=0$, female $=1)$, age (continuous, in years), marital status (single/separated/divorced/ widowed $=0$, married $=1$ ), number of other persons in the household (continuous), educational level (continuous, in years), occupational position (three categories: unemployed $=0$, lower managerial, artisans, commercial $=1$, high professional, managerial $=2$ ), perception of personal health status (continuous), belief that CRC can be prevented (no $=0$, yes $=1)$, participation in preventive activities about CRC (no $=0$, yes $=1)$, physician as source of information about CRC (no $=0$, yes $=1)$, and need of additional information about CRC $($ no $=0$, yes $=1)$. The following variables were also included: modify the dietary habits for fear of contracting CRC (no $=0$, yes $=1$ ), performing physical activity ( $\mathrm{no}=0$, yes $=1$ ), and modify the physical activity for fear of contracting CRC (no $=0$, yes $=$ 1 ) in Model 1; knowledge of risk factors of CRC (low physical activity, high caloric intake from fat, polyps, familial history of precancerous lesions or of CRC) ( no = 0 , yes $=1$ ), and advice received by a physician of performing FOBT ( $\mathrm{no}=0$, yes $=1$ ) in Model 2; knowledge of FOBT as main test for CRC prevention ( $\mathrm{no}=0$, yes $=1$ ) in Model 3; personal history of precancerous lesions and familial history of precancerous lesions or CRC (no $=0$, yes $=1$ ) and recommendation by a physician for undergone or not undergone FOBT (no = 0 , yes $=1$ ) in Model 4; BMI (continuous) and knowledge of the definition of CRC ( $\mathrm{no}=0$, yes $=1$ ) in Models 1 and 2; personal perceived risk of contracting CRC (continuous) and personal or familial history of precancerous lesions or CRC (no $=0$, yes $=1)$ in Models 1-3; knowledge of the main unmodifiable risk factors of CRC (polyps, familial history of precancerous lesions or CRC) (no = 0 , yes $=1$ ) in Models 1 and 3; positive attitude towards the utility of tests for CRC prevention (continuous) in Models 2 and 4. The significance level for variables entering the logistic and linear regression models was set at 0.2 and for removing from the model at 0.4. Odds ratios (ORs) and 95\% confidence intervals (CIs) were calculated with the use of logistic regression analyses. All of the tests for significance were two-sided and $p$-values $\leq 0.05$ were considered statistically significant. All analyses were conducted using the Stata software program, version 8.1 [22].

\section{Results}

A total of 595 subjects returned the self-administered questionnaire with an overall response rate of $51 \%$. The principal characteristics of the study group are shown in Table 1 . The mean age of participants was 44 years, twothirds were females, one-third had a college degree, and $0.8 \%$ and $11.6 \%$ reported a personal or familial history of precancerous lesions or CRC, respectively.

Table 2 summarizes the data concerning the level of knowledge about CRC risk factors and prevention strategies in the study population. An overall evaluation of the answers revealed a poor level of knowledge, with most of the respondents giving wrong answers. In particular, less than one-third (30.1\%) were able to give the definition of $\mathrm{CRC}$ and a wide range of responses were given regarding the factors believed as potentially CRC causing. Thus, $24 \%$ to $62.9 \%$ correctly identified that low physical activity and polyps were risk factors for CRC and $54.1 \%$ to 99.3\% that bowel infections and fruit and vegetable intake should not be risk factors. Overall, only $18.5 \%$ knew that low physical activity and high caloric intake from fat were the two main modifiable risk factors. The results of the knowledge about the preventive measures showed that $51.8 \%$ correctly identified FOBT as main test for CRC prevention. Results of the multiple logistic regression analysis indicated that five variables were statistically and independently associated with the knowledge that low physical activity and high caloric intake from fat were the two main modifiable risk factors: higher educational level ( $\mathrm{OR}=1.08 ; 95 \% \mathrm{CI} 1.03-1.15)$, performing physical activity $(\mathrm{OR}=1.79 ; 95 \%$ CI $1.14-2.83)$, modification of dietary habits $(\mathrm{OR}=1.92 ; 95 \%$ CI $1.07-3.46)$ and of physical activity for fear of contracting CRC $(\mathrm{OR}=2.22$; 95\% CI 1.1-4.49), and lower risk perception of contracting CRC (OR $=0.91 ; 95 \%$ CI 0.83-0.99) (Model 1 in Table 3). The second outcome of interest was the knowledge of FOBT as main test for CRC prevention and respondents were more likely to have this knowledge if they were unmarried $(\mathrm{OR}=0.47 ; 95 \% \mathrm{CI} 0.23-0.95)$, more educated $(\mathrm{OR}=1.08 ; 95 \% \mathrm{CI} 1.03-1.13)$, knew the risk factors of CRC (OR $=1.87 ; 95 \%$ CI 1.04-3.38), and had received advice by a physician of performing FOBT $(\mathrm{OR}=3.43 ; 95 \%$ CI 2.01-5.83) (Model 2 in Table 3).

With regard to the attitudes, $60.3 \%$ and $78.5 \%$ respectively responded that it is possible to prevent CRC and to treat the cancer in case of an early diagnosis. Participants were also asked to rate their perceived risk of contracting CRC and the mean score was 5.1, indicating low level of risk perception, with only $9.7 \%$ asserted a high degree of concern by answering "10". Personal opinion that screening is useful for CRC prevention was generally rated high with a mean score of 8.3 and $48.6 \%$ indicated a score of "10". Variables associated with the positive attitude 
Table I: Socio-demographic characteristics and selected information about the study population

\begin{tabular}{|c|c|c|}
\hline & $n$ & $\%$ \\
\hline \multicolumn{3}{|l|}{ Gender } \\
\hline Female & 396 & 66.6 \\
\hline Male & 199 & 33.4 \\
\hline Age (years) & $44.2 \pm 5.8(31-67)^{*}$ & \\
\hline \multicolumn{3}{|l|}{ Marital status } \\
\hline Married & 556 & 93.4 \\
\hline Other & 39 & 6.6 \\
\hline \multicolumn{3}{|l|}{ Number of other persons in the household } \\
\hline 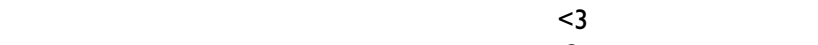 & 64 & 10.8 \\
\hline 3 & 341 & 57.3 \\
\hline 4 & 138 & 23.2 \\
\hline$\geq 5$ & 52 & 8.7 \\
\hline Educational level (years) & $14.2 \pm 4^{*}$ & \\
\hline (1) & 12 & 2 \\
\hline $8-12$ & 124 & 20.8 \\
\hline $13-17$ & 314 & 52.8 \\
\hline$>17$ & 145 & 24.4 \\
\hline \multicolumn{3}{|l|}{ Occupational position } \\
\hline Unemployed & 144 & 24.2 \\
\hline Lower managerial, artisans, commercial & 346 & 58.2 \\
\hline High professional, managerial & 105 & 17.6 \\
\hline Perception of personal health status & $7.5 \pm 1.6(5-30)^{*}$ & \\
\hline \multicolumn{3}{|l|}{ Personal history of precancerous lesions } \\
\hline 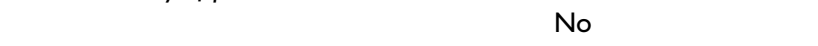 & 590 & 99.2 \\
\hline Yes & 5 & 0.8 \\
\hline \multicolumn{3}{|l|}{ Personal history of colorectal cancer } \\
\hline 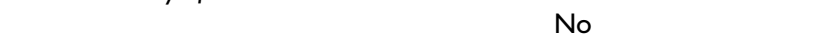 & 594 & 99.8 \\
\hline Yes & 1 & 0.2 \\
\hline \multicolumn{3}{|l|}{ Familial history of precancerous lesions or colorectal cancer } \\
\hline No & 526 & 88.4 \\
\hline Yes & 69 & 11.6 \\
\hline
\end{tabular}

*Mean \pm Standard deviation (Range)

towards the utility of screening for CRC prevention at $p$ value $\leq 0.25$ at univariate level were entered into multivariable linear regression model. The most important variables that predicted this positive attitude were respondents' beliefs that CRC can be prevented and a high personal perceived risk of contracting CRC. Respondents with lower educational level and those who have received information about CRC from a physician were also significantly more likely to have this positive attitude (Model 3 in Table 3).

Of the survey respondents, 118 (19.9\%) were eligible for performing FOBT according to the recommended Italian guidelines. With regard to participants' prior adherence to such recommendations, $72.7 \%$ reported having an appropriate behavior in undergoing FOBT if eligible or not undergoing FOBT if not eligible. Those younger $(\mathrm{OR}=$ 0.85 ; 95\% CI 0.81-0.9), female (OR $=1.62 ; 95 \%$ CI $1.01-$ 2.62), more educated $(\mathrm{OR}=1.07 ; 95 \%$ CI 1.01-1.13), with no personal history of precancerous lesions and familial history of precancerous lesions or CRC $(\mathrm{OR}=$ 0.29 ; 95\% CI $0.15-0.54)$, and who had been recom- mended by a physician to undergone or not undergone FOBT (OR $=4.62 ; 95 \%$ CI 2.82-7.58) were more likely to have had an appropriate behavior (Model 4 in Table 3 ). Of those who did not undergo the test, 19.5\% were eligible, but the main reasons were lack of proper counsel by physicians and also that they felt healthy.

In terms of information, $60 \%$ of the respondents recalled receiving information regarding $\mathrm{CRC}$ and the most common sources had been the media $(40.8 \%)$ and the physicians $(15.8 \%)$. Interestingly, $75 \%$ of the respondents indicated that they would like more information about CRC.

\section{Discussion}

This study sheds light on a group of adults in an area of Italy regarding the level of understanding community knowledge, attitudes, and preventive practices about CRC and it provides information for educators and policy makers that is necessary for guidance towards preventive campaigns. Previous research conducted in other countries exploring this topic typically focused on subjects aged fifty 
Table 2: Knowledge about colorectal cancer in the study population

\begin{tabular}{|c|c|c|c|c|c|c|}
\hline & \multicolumn{4}{|c|}{ Correctly answered } & \multicolumn{2}{|c|}{ Do not know } \\
\hline & Yes & $\%$ & No & $\%$ & $n$ & $\%$ \\
\hline Definition & 179 & 30.1 & 416 & 69.9 & - & - \\
\hline \multicolumn{7}{|l|}{ Risk factors } \\
\hline Polyps & 374 & 62.9 & 221 & 37.1 & - & - \\
\hline Familial history of colorectal cancer & 321 & 53.9 & 274 & 46.1 & - & - \\
\hline High caloric intake from fat & 279 & 46.9 & 316 & 53.1 & - & - \\
\hline Cigarette smoking & 160 & 26.9 & 435 & 73.1 & - & - \\
\hline Low physical activity & 143 & 24 & 452 & 76 & - & - \\
\hline \multicolumn{7}{|l|}{ No risk factors } \\
\hline Fruit and vegetables intake & 591 & 99.3 & 4 & 0.7 & - & - \\
\hline Hypertension & 585 & 98.3 & 10 & 1.7 & - & - \\
\hline Oral contraceptives use & 584 & 98.2 & 11 & 1.8 & - & - \\
\hline Diabetes & 570 & 95.8 & 25 & 4.2 & - & - \\
\hline Bowel infections & 322 & 54.1 & 273 & 45.9 & - & - \\
\hline \multicolumn{7}{|l|}{ Preventive measures } \\
\hline Colonoscopy & 373 & 62.7 & 106 & 17.8 & 116 & 19.5 \\
\hline Fecal occult blood testing & 308 & 51.8 & 161 & 27 & 126 & 21.2 \\
\hline Double contrast barium enema & 154 & 25.9 & 289 & 48.6 & 152 & 25.5 \\
\hline Sigmoidoscopy & 62 & 10.4 & 360 & 60.5 & 173 & 29.1 \\
\hline \multicolumn{7}{|l|}{ No preventive measures } \\
\hline Blood test & 255 & 42.8 & 226 & 38 & 114 & 19.2 \\
\hline Ecography & 249 & 41.9 & 222 & 37.3 & 124 & 20.8 \\
\hline
\end{tabular}

years or older [9-19]. Our study differs in that we analyzed a younger population and the main reason for our sample selection was that we felt that special attention should be paid to them because we are confident that prior behaviors in targeting promotion and information may have important public health implications in order to further increase understanding of CRC and performing appropriate preventive practices.

In the current study, the results indicated a general lack of knowledge and there are some important gaps. In regard to the responses to individual items, it is of some concern that fewer than one-third of the subjects surveyed were able to define $\mathrm{CRC}$, the percentages of those correctly answering the questions on risk factors ranged from $24 \%$ for low physical activity to $62.9 \%$ for polyps, while $51.8 \%$ correctly identified FOBT as main test for the prevention of CRC. Previous studies conducted in other countries suggest a similar low level of knowledge about preventive measures. Indeed, in the United States, in a group of 104 patients $\geq 50$ years of age from medical clinics, $69.2 \%$ and $49 \%$, respectively, identified colonoscopy and FOBT as the main screening tests for the prevention of CRC [15] and in a population-based study of 105 white males 5079 years of age, $75 \%$ had heard of colonoscopy [11]. Better awareness has been acknowledge in a group of 648 individuals aged $45-66$ years in south-west England since $42.2 \%$ and $43.3 \%$ identified inactivity and smoking as risk factors, respectively [9]. Our findings that the respondents more educated, unmarried, with lower per- sonal perceived risk of contracting CRC, and who had received advice by a physician were more likely to provide a correct response to the questions concerning modifiable risk factors and FOBT for CRC prevention suggest that information about CRC is not yet widely disseminated. The possible interpretation that those with lower personal perceived risk of contracting CRC were more likely to have a higher level of knowledge is that they are particularly motivated to acquire information at an early stage. Moreover, this is also supported by the association, although not statistically significant, with the participation in preventive activities and this emphasizes the crucial role of the physician in influencing patient knowledge.

Our findings concerning attitudes towards both the prevention of CRC in general and its screening tests in particular are encouraging, with a relatively high mean score on the utility of tests. Although respondents reported gaining information from a variety of sources, they again demonstrated very high levels of trust in physicians. Indeed, as revealed by multivariate analysis, this study demonstrates an association between information delivered by physicians and positive attitudes, since those identifying a physician as their primary source of information about CRC had the highest mean attitude score. So, because only $15.8 \%$ of respondents claimed to receive information about CRC from physicians, this avenue of support can be significantly strengthened. It is precisely this specific kind of information that might be required to satisfy the large 
Table 3: Multivariate logistic $(I, 2,4)$ and linear (3) regression analyses indicating associations between several variables and the different outcomes

\begin{tabular}{|c|c|c|c|}
\hline Variable & OR & $95 \% \mathrm{Cl}$ & $p$ \\
\hline \multicolumn{4}{|c|}{ Model I. Knowledge of the two main modifiable risk factors of colorectal cancer (low physical activity, high caloric intake from fat) } \\
\hline \multicolumn{4}{|c|}{ Log likelihood $=-265.58, \chi^{2}=38.5 \mathrm{I}(5 \mathrm{df}), p<0.000 \mathrm{I}$} \\
\hline \multicolumn{4}{|c|}{ Educational level } \\
\hline Higher & 1.08 & $1.03-1.15$ & 0.004 \\
\hline \multicolumn{4}{|l|}{ Performing physical activity } \\
\hline No & $1.0^{*}$ & & \\
\hline Yes & 1.79 & $1.14-2.83$ & 0.012 \\
\hline \multicolumn{4}{|c|}{ Physical activity modified for fear of contracting colorectal cancer } \\
\hline No & $1.0^{*}$ & & \\
\hline Yes & 2.22 & $1.1-4.49$ & 0.027 \\
\hline \multicolumn{4}{|c|}{ Personal perceived risk of contracting colorectal cancer } \\
\hline Lower & 0.91 & $0.83-0.99$ & 0.028 \\
\hline \multicolumn{4}{|c|}{ Dietary habits modified for fear of contracting colorectal cancer } \\
\hline No & $1.0^{*}$ & & \\
\hline Yes & 1.92 & $1.07-3.46$ & 0.029 \\
\hline \multicolumn{4}{|c|}{ Model 2. Knowledge of fecal occult blood testing as main test for colorectal cancer prevention } \\
\hline \multicolumn{4}{|c|}{ Log likelihood $=-379.53, \chi^{2}=65.05(8 \mathrm{df}), p<0.0001$} \\
\hline \multicolumn{4}{|c|}{ Advice received by physician of performing fecal occult blood testing } \\
\hline No & $1.0 *$ & & \\
\hline Yes & 3.43 & $2.01-5.83$ & $<0.001$ \\
\hline \multicolumn{4}{|l|}{ Educational level } \\
\hline Higher & 1.08 & $1.03-1.13$ & 0.001 \\
\hline \multicolumn{4}{|l|}{ Marital status } \\
\hline Single/separated/divorced/widowed & $1.0^{*}$ & & \\
\hline Married & 0.47 & $0.23-0.95$ & 0.035 \\
\hline \multicolumn{4}{|c|}{ Knowledge of risk factors of colorectal cancer } \\
\hline No & $1.0 *$ & & \\
\hline Yes & 1.87 & $1.04-3.38$ & 0.037 \\
\hline \multicolumn{4}{|c|}{ Participation in preventive activities about colorectal cancer } \\
\hline No & $1.0 *$ & & \\
\hline Yes & 3.19 & $0.83-12.27$ & 0.09 \\
\hline \multicolumn{4}{|c|}{ Physician as source of information about colorectal cancer } \\
\hline No & $1.0 *$ & & \\
\hline Yes & 1.43 & $0.88-2.33$ & 0.15 \\
\hline \multicolumn{4}{|c|}{ Belief that colorectal cancer can be prevented } \\
\hline No & $1.0 *$ & & \\
\hline Yes & 1.22 & $0.86-1.74$ & 0.26 \\
\hline \multicolumn{4}{|c|}{ Personal or familial history of precancerous lesions or colorectal cancer } \\
\hline No & $1.0 *$ & & \\
\hline Yes & 1.36 & $0.8-2.31$ & 0.26 \\
\hline
\end{tabular}

Model 4. Appropriate behavior in undergoing fecal occult blood testing if eligible or not undergoing fecal occult blood testing if not eligible Log likelihood $=-238.38, \chi^{2}=219.35(6 \mathrm{df}), p<0.0001$

Age Younger

Personal history of precancerous lesions and familial history of precancerous lesions or colorectal cancer No

$0.85 \quad 0.81-0.9<0.001$

Yes

I.0*

Recommendation by a physician for undergone or not undergone fecal occult blood testing No

Yes

Educational level Higher

Gender

Male

Female

$1.0 *$

$4.62 \quad 2.82-7.58<0.001$

$1.07 \quad 1.01-1.13 \quad 0.034$

Number of other persons in the household 
Table 3: Multivariate logistic $(I, 2,4)$ and linear (3) regression analyses indicating associations between several variables and the different outcomes (Continued)

\begin{tabular}{|c|c|c|c|}
\hline Higher & 1.14 & $0.87-1.49$ & 0.34 \\
\hline Variable & Coeff. & $\mathrm{t}$ & $p$ \\
\hline \multicolumn{4}{|c|}{ Model 3. Positive attitude towards the utility of screening tests for colorectal cancer prevention } \\
\hline \multicolumn{4}{|c|}{$F(6,588)=12.95, p<0.0001, R^{2}=11.7 \%$, adjusted $R^{2}=10.8 \%$} \\
\hline Personal perceived risk of contracting colorectal cancer & 0.11 & 3.65 & $<0.001$ \\
\hline Belief that colorectal cancer can be prevented & 1.13 & 6.87 & $<0.001$ \\
\hline Educational level & -0.05 & -2.73 & 0.007 \\
\hline Physician as source of information about colorectal cancer & 0.49 & 2.27 & 0.024 \\
\hline Perception of personal health status & 0.05 & 1.03 & 0.3 \\
\hline Gender & -0.16 & -0.92 & 0.36 \\
\hline Constant & 7.68 & & \\
\hline
\end{tabular}

*Reference category

percentage $(75 \%)$ who indicated that they would need more information about CRC.

In our responders, the vast majority reported appropriate behavior regarding the periodicity with which subjects ought to be screened. Indeed, $72.7 \%$ reported having appropriate behavior in undergoing FOBT if eligible or not undergoing FOBT if not eligible according to Italian guidelines. The most frequently cited reasons by the respondents for not having yet undergone FOBT were that these had not been recommended by a physician and that they felt healthy. This finding is consistent with a study conducted in Canada among a group of relatives of CRC patients [13]. Still, it is troubling that $19.5 \%$ of those who never undergone FOBT were eligible. As expected, recommendation by a physician for undergoing or not undergoing FOBT has a positive influence to improve appropriate behavior.

The results of the study should be interpreted in light of some potential limitations. First, this was a cross-sectional study and as such it does not permit the establishment of a casual relationship between the different variables and CRC. Second, the use of self-administered questionnaires to measure behavior and perceptions, like all similar surveys, may allow the possibility either that the responses may be incomplete or may not reflect the truth with people who may have responded differently. We are confident that such problems are minimal because the questionnaires had not missing data and the responses were self-reported in a confidential and anonymous setting. Third, the representativeness of our sample may be limited by the response rate at $51 \%$, though not uncommon in such studies, and it is equally possible that a nonresponse bias of those who responded may have characteristics that made them different from those who did not respond. Although the low response rate does not affect the internal validity of the findings, it may decrease the generalizability of the results. However, respondents did not differ significantly from the population of the same area with respect to the principal socio-demographic characteristics, thus the findings may be generalized.

\section{Conclusion}

In summary, our data clearly indicate that linkages between health care and educational systems will be vital to improve levels of knowledge and understanding of CRC preventive measures and to improve screening adherence.

\section{Competing interests}

The authors declare that they have no competing interests.

\section{Authors' contributions}

AS participated in the design of the study, data collection, statistical analysis, and interpretation of the data. RA participated in the statistical analysis and interpretation of the data. GDG participated in the design of the study and data collection. PM participated in the design of the study and interpretation of the data. IFA, the principal investigator, designed the study, was responsible for the data collection, statistical analysis and interpretation of the data, and wrote the article. All Authors read and approved the final manuscript.

\section{Additional material}

\section{Additional File 1}

QuestionnaireColon: Questionnaire used in the survey.

Click here for file

[http://www.biomedcentral.com/content/supplementary/1471-

2407-8-171-S1.doc]

\section{Acknowledgements}

Preliminary results were presented at the Research Meeting of the Second University of Naples, July 2-7, 2007, Naples, Italy. 
The authors are grateful to the participants who took part in the survey.

\section{References}

I. Parkin DM, Bray F, Ferlay J, Pisani P: Global Cancer Statistics, 2002. CA Cancer J Clin 2005, 55:74-108.

2. Giovannucci E: Modifiable risk factors for colon cancer. Gastroenterol Clin North Am 2002, 3 I:925-943.

3. Jemal A, Siegel R, Ward E, Hao Y, Xu J, Murray T, Thun MJ: Cancer Statistics, 2008. CA Cancer J Clin 2008, 58:71-96.

4. Associazione Italiana Registri Tumori (AIRTum): Banca dati AIRTum. [http://www.registri-tumori.it/cms/?q=database airtum]. (Accessed on March 20, 2008)

5. Associazione Italiana Registri Tumori (AIRT) Working Group: Italian cancer figures - Report 2006: I. Incidence, mortality and estimates. Epidemiol Prev 2006, 30(Suppl 2): I-I48.

6. Arbyn M, Van Oyen H, Lynge E, Micksche M, Faivre J, Jordan J: European Commission's proposal for a council recommendation on cancer screening. BMJ 2003, 327:289-290.

7. Zorzi M, Barca A, Falcini F, Grazzini G, Pizzuti R, Ravaioli A, Sassoli de Bianchi P, Senore C, Sigillito A, Vettorazzi M, Visioli C: Screening for colorectal cancer in Italy: 2005 survey. Epidemiol Prev 2007, 3 I(2-3 Suppl 2):49-60.

8. Ministero della Salute: Raccomandazioni per la pianificazione e l'esecuzione degli screening di popolazione per la prevenzione del cancro della mammella, del cancro della cervice uterina e del cancro del colon retto. [http:www.osservatorionazionalescreening.it/ons/documentazione/ racco mandazioni.htm]. (Accessed on March 17, 2008)

9. Robb KA, Miles A, Campbell J, Evans P, Wardle J: Can cancer risk information raise awareness without increasing anxiety? $A$ random trial. Prev Med 2006, 43:187-190.

10. Shapiro JA, Seeff LC, Nadel MR: Colorectal cancer-screening tests and associated health behaviors. Am J Prev Med 2001, 2I:132-137.

II. Janz NK, Wren PA, Schottenfeld D, Guire KE: Colorectal cancer screening attitudes and behavior: a population-based study. Prev Med 2003, 37:627-634.

12. Farraye FA, Wong M, Hurwitz S, Puleo E, Emmons K, Wallace MB, Fletcher RH: Barriers to endoscopic colorectal cancer screening: are women different from men? Am J Gastroenterol 2004, 99:34I-349.

13. Madlensky L, Esplen MJ, Goel V: Reasons given by relatives of colorectal cancer patients for not undergoing screening. Prev Med 2004, 39:643-648.

14. Weinberg DS, Turner BJ, Wang H, Myers RE, Miller S: A survey of women regarding factors affecting colorectal cancer screening compliance. Prev Med 2004, 38:669-675.

15. Matthews BA, Anderson RC, Nattinger AB: Colorectal cancer screening behavior and health insurance status (United States). Cancer Causes Control 2005, I 6:735-742.

16. Wee CC, McCarthy EP, Phillips RS: Factors associated with colon cancer screening: the role of patient factors and physician counseling. Prev Med 2005, 41:23-29.

17. Schenck AP, Klabunde CN, Davis WW: Racial differences in colorectal cancer test use by Medicare consumers. Am J Prev Med 2006, 30:320-326.

18. Coups EJ, Manne SL, Meropol NJ, Weinberg DS: Multiple behavioral risk factors for colorectal cancer and colorectal cancer screening status. Cancer Epidemiol Biomarkers Prev 2007, 16:510-516.

19. Robb KA, Miles A, Wardle J: Perceived risk of colorectal cancer: sources of risk judgments. Cancer Epidemiol Biomarkers Prev 2007, 1 6:694-702.

20. Crerand CE, Wadden TA, Sarwer DB, Fabricatore AN, Kuehnel RH, Gibbons LM, Brock JR, Williams NN: A comparison of weight histories in women with class III vs. class I-II obesity. Surg Obes Relat Dis 2006, 2:165-I70.

21. Inoue M, Toyokawa S, Miyoshi Y, Miyano Y, Suzuki T, Suyama Y, Inoue K, Kobayashi $Y$ : Degree of agreement between weight perception and body mass index of Japanese workers: MY Health Up Study. J Occup Health 2007, 49:376-38I.

22. Stata Corporation: Stata Reference Manual Release 8.I College Station, TX, USA; 2003.

\section{Pre-publication history}

The pre-publication history for this paper can be accessed here:

http://www.biomedcentral.com/1471-2407/8/171/pre pub
Publish with Bio Med Central and every scientist can read your work free of charge

"BioMed Central will be the most significant development for disseminating the results of biomedical research in our lifetime. "

Sir Paul Nurse, Cancer Research UK

Your research papers will be:

- available free of charge to the entire biomedical community

- peer reviewed and published immediately upon acceptance

- cited in PubMed and archived on PubMed Central

- yours - you keep the copyright

Submit your manuscript here:

http://www.biomedcentral.com/info/publishing_adv.asp
BioMedcentral 